NBER WORKING PAPER SERIES

\title{
EXPLAINING SUDDEN STOPS, GROWTH COLLAPSE AND BOP CRISES: THE CASE OF DISTORTIONARY OUTPUT TAXES
}

\author{
Guillermo A. Calvo \\ Working Paper 9864 \\ http://www.nber.org/papers/w9864 \\ NATIONAL BUREAU OF ECONOMIC RESEARCH \\ 1050 Massachusetts Avenue \\ Cambridge, MA 02138 \\ July 2003
}

I am grateful to Fernando Broner, Kevin Cowan, Alejandro Izquierdo, Michael Kumhof, Eduardo LevyYeyati, Luis Fernando Mejía, Enrique Mendoza, Ned Phelps, Ernesto Talvi, and seminars participants at IADB, Di Tella University and the University of Maryland for valuable comments. This paper was prepared for the Mundell-Fleming Lecture at the IMF Annual Research Conference, November 7, 2002. I would like to dedicate it to the memory of Rudi Dornbusch, whose insight, wit and whip inspired generations of scholars and policymakers in International Finance and Development Economics. The views expressed herein are those of the authors and not necessarily those of the National Bureau of Economic Research

(C)2003 by Guillermo A. Calvo. All rights reserved. Short sections of text not to exceed two paragraphs, may be quoted without explicit permission provided that full credit including $(\mathrm{C}$ notice, is given to the source. 
Explaining Sudden Stops, Growth Collapse and BOP Crises:

The Case of Distortionary Output Taxes

Guillermo A. Calvo

NBER Working Paper No. 9864

July 2003

JEL No. F3, F4

\begin{abstract}
The paper discusses a model in which growth is a negative function of fiscal burden. Moreover, growth discontinuously switches from high to low as fiscal burden reaches a critical level. Growth collapse is associated with a Sudden Stop of capital inflows, real depreciation and a drop in output (driven by a fall in the output of nontradables)-all of which have occurred during recent financial crises in Emerging Markets. The monetary version of the model is employed to show that BOP crises could be a result of fiscal distortions. In particular, it is further argued that BOP crisis could be a justifiable central bank response to growth collapse, although realistic circumstances may make this response highly ineffective. An important policy implication of the model is that in order to avoid Sudden Stop crises, policymakers should aim at improving fiscal institutions. Lowering the fiscal deficit is highly effective in the medium term, but could be counterproductive in the short run if it relies on higher taxes.

Guillermo A. Calvo

Chief Economist

Inter-American Development Bank

1300 New York Avenue

Washington, DC 20005

and NBER

calvo@econ.umd.edu
\end{abstract}




\section{Introduction}

Since Mexico's Tequila Crisis of 1994/5, Emerging Market Economies, EM, have entered a period of recurrent crises that go far beyond currency crises as experienced in Advanced Economies. EM crises are characterized by sharp recession, high unemployment, and

\section{(Insert Table 1 here)}

an alarming rise in the number of people living below the poverty line. A common feature of these episodes is a Sudden Stop, SS, namely, a large reduction in the flow of international capital. ${ }^{1}$ This is illustrated in Table 1 which, incidentally, shows that the phenomenon predates the Tequila. Moreover, Calvo and Reinhart (2001) show that, on the whole, SS is absent in Advanced Countries. This leads me to the conjecture that SS is perhaps the central feature of EM crises from which all the others follow. Developing a theory that rationalizes the conjecture is a challenging task, because EM crises have not been preceded by sharply deteriorating fundamentals (see Calvo and Mendoza (1996 a and b) for the case of Mexico). Thus, to model this fact the theory should ideally be able to display market equilibrium discontinuity as a function of market fundamentals.

The basic model presented at the outset exhibits equilibrium discontinuity. A key assumption is that government expenditure has to be partly financed by output taxes which, by their nature, lower the after-tax marginal value productivity of capital. Thus, the larger is government expenditure, the lower will be the rate of growth. There is a region, however, where high and low growth equilibria coexist. The intuition for this is

\footnotetext{
${ }^{1}$ The expression Sudden Stop was first suggested, and the phenomenon highlighted, in Dornbusch et al (1995).
} 
straightforward: high (low) growth implies low (high) tax rates, sustaining high (low) growth. The model assumes that International Financial Institutions, IFIs, will realize that equilibrium indeterminacy is all a matter of expectations, and will help to coordinate the high-growth equilibrium. Thus, equilibrium is unique. ${ }^{2}$ However, a discontinuity will take place at the point where multiplicity disappears, and only low growth can be sustained. This happens in the model when government expenditure (summarized by the stock of public debt) which has to be serviced by output taxes reaches a critical level. If the economy is near that critical level, seemingly minor accidents, like a deterioration of the terms of trade or an increase in country risk, could throw the economy into the region where only low growth is sustainable. Moreover, since investment collapses, a SS will take place. The model is then extended to account for nontradable or home goods. In that context, it is shown that if the crisis contains an unanticipated component, then the SS will be accompanied by an increase in the real exchange rate (i.e., real devaluation). ${ }^{3}$

Finally, the model is extended to incorporate money in a cash-in-advance fashion. Since money demand is positively correlated with aggregate demand, a collapse of the latter (discussed at the end of last paragraph) would bring about a drop in the demand for money. Thus, if the exchange rate is fixed, international reserves will fall precipitously, resembling a BOP crisis. The monetary economy is then employed to study optimal exchange rate policy in response to SS. Since SS is, after all, a cut in total credit, it may

\footnotetext{
${ }^{2}$ For an earlier attempt to rationalize SS on the basis of multiplicity of equilibria and in an essentially static non-monetary framework, see Calvo (1998 b).

${ }^{3}$ Real depreciation also takes place if the crisis is fully anticipated and it entails a higher consumption tax, for example.
} 
be optimal for the central bank to release some of its international reserves (e.g., through credit subsidy) to relieve the impact of SS on the private sector, especially when the new credit conditions contain an important surprise element. Under the usual rules that dictate the operation of a central bank, the latter can release reserves by expanding domestic credit and pegging the exchange rate (pure floating would not do because in that case international reserves will remain intact). This reaction to SS has been quite common in EM. Therefore, the central bank may end up precipitating the BOP crisis. This policy, incidentally, is criticized in the paper by indicating that the recipients of central bank largesse may not be the intended target. The paper argues that if policymakers understand this difficulty, they may be driven to experiment with heterodox policies (like directing credit to specific sectors).

\section{Basic Model}

The basic structure of this model is taken from Calvo (1998 c) which, in turn, is a dynamic extension of Eaton (1987). I will start by examining the case of an economy that produces tradable output by means of tradable capital, $K$. The production function is linear homogeneous: one unit of output is produced by means of $1 / \alpha$ units of capital. The net cash-flow, $S$, for a firm that accumulates capital at the rate $\dot{K}$ is given by (assuming away capital depreciation):

$$
S_{t}=\alpha(1-\tau) K_{t}-\dot{K}_{t},
$$

where $\tau, 0 \leq \tau \leq 1$, denotes the constant output tax rate. Thus, denoting the constant international real interest rate (i.e., the own-rate of return on output) by $r$, the value of the firm at time zero, $V$, is given by 


$$
V=\int_{0}^{\infty} S_{t} e^{-r t} d t
$$

Hence, assuming that $K_{0}=1$, and setting $z \equiv \dot{K} / K$ yields

$$
V=\int_{0}^{\infty}\left[\alpha(1-\tau)-z_{t}\right] e^{-\int_{0}^{t}\left(r-z_{s}\right) d s} d t
$$

Notice, incidentally, that given linear technology $z$ equals the rate of output growth.

The firm is assumed to maximize $V$ by choosing the growth path $z$, taking as given the international interest rate $r$, the tax rate $\tau$, and the technological constraints. A quick inspection of this problem shows that the optimum can be found among the constant-z paths, in which case equation (3) can be expressed as:

$$
V=\frac{\alpha(1-\tau)-z}{r-z}
$$

Differentiating the right-hand side of equation (4) with respect to $z$, yields

$$
\operatorname{sgn} \frac{\partial V}{\partial z}=\operatorname{sgn}[\alpha(1-\tau)-r]
$$

Therefore, as expected, the firm will grow as fast (slow) as possible if the net-of-tax marginal productivity of capital exceeds (falls short of) the rate of interest. Thus, in order to obtain well-defined solutions, one must constraint $z$ to a finite interval, and $z<r$. Concretely, I will assume that there exists some $\bar{z}>0$ such that $0 \leq z \leq \bar{z}<r$. Setting 0 as the lower bound implies that capital cannot by unbolted; thus, the model belongs to the putty-clay family.

The next step is to endogenize the tax rate $\tau$. I will assume that the government inherits a stock of debt $D$, a share $\theta$ of which has to be serviced by means of output taxes. Again, assuming that the government has full access to capital markets, the tax rate $\tau$ 
must be such that

$$
\theta D=\alpha \tau \int_{0}^{\infty} K_{t} e^{-r t} d t=\frac{\alpha \tau}{r-z}
$$

Thus, using equation (6) in expression (5), we get the following fundamental relationship:

$$
\operatorname{sgn} \frac{\partial V}{\partial z}=\operatorname{sgn}[\alpha-\theta D(r-z)-r]
$$

Notice that the bracketed expression in equation (7) increases with $z$. Thus, the Low Growth Equilibrium, LGE, i.e., $z=0$, is possible if

$$
\alpha-\theta D r-r<0
$$

In other words, LGE exists if as firms set $z=0$, they have no incentive, by expression (8), to revise their choice. It is worth noting, however, that this does not rule out the existence of other equilibria.

On the other hand, by a similar reasoning, the High Growth Equilibrium, HGE, i.e., $z=\bar{z}$, exists if

$$
\alpha-\theta D(r-\bar{z})-r>0
$$

The left-hand-side functions in expressions (8) and (9) are drawn in Figure 1. ${ }^{4}$ Clearly, LGE exists if $\theta D>\delta^{1}=(\alpha-r) / r$, while HGE exists if $\theta D<\delta^{2}=(\alpha-r) /(r-\bar{z})$. Thus, indeterminacy exists in the interval $\left(\delta^{1}, \delta^{2}\right)$. However, coordination among investors could drive the economy to the HGE. Success of this policy could be greatly aided by strong support from IFIs, requiring, in principle, no public sector resources. For, eliminating the bad LGE in the indeterminacy region is, in principle, a costless

\footnotetext{
${ }^{4}$ The borderline cases in which (8) or (9) hold with equality are of no interest and will not be discussed here.
} 
operation. Thus, I will assume that if LGE and HGE coexist, the economy will always settle at the HGE. ${ }^{5}$

\section{(Insert Figure 1 here)}

Consequently, the model implies high growth if $\theta D \leq \delta^{2}$, and low growth (actually, zero growth) otherwise. Equilibrium discontinuity (see Figure 2) is a key result because it helps to rationalize situations in which, all of a sudden, a roaring tiger becomes a whining pussycat. This feature is, unfortunately, somewhat clouded in the present model, given that linear production functions generate, as a general rule, corner solutions. Thus, the equilibrium discontinuity highlighted here may appear as a trivial and uninteresting proposition. To dispel that view the Appendix will "smooth the edges" of this model by assuming adjustment costs to investment. As shown there, under uniqueness, growth is a continuous and negative function of $D$. It takes equilibrium multiplicity as depicted in the above model (prior to the equilibrium selection criterion adopted here, which in case of indeterminacy picks the one yielding the highest growth) to generate discontinuity. Growth discontinuity takes place as the systems loses a good equilibrium and plunges to an equilibrium exhibiting lower growth. Notice that, although equilibrium multiplicity is a necessary condition to obtain growth collapse, it is not sufficient. For example, it is easy to construct examples exhibiting two equilibria in which equilibrium solutions converge to each other as debt goes up. Thus, growth

\footnotetext{
${ }^{5}$ In my view the IFI's coordination role was successfully carried out in Mexico 1995, Korea 1997 and Brazil 1999, and helps to explain the rapid (V-shaped) recovery of those economies.
} 
collapse as depicted in the above model never takes place. Instead, what one would have is a situation in which, except for a borderline case, the model yields two equilibria or none at all. Therefore, the set of models that yield growth collapse are strictly included in those yielding equilibrium multiplicity (before imposing the equilibrium-selection criterion). Thus, the existence of realistic examples yielding growth collapse cannot be taken for granted, which opens up an interesting research agenda.

(Insert Figure 2 here)

In what follows, I will continue the discussion in terms of the present model because SS and other interesting implications are the same as in the more complex model presented in the Appendix (except in the few instances in which it will be explicitly noted).

The model or simple extensions provide interesting insights. For example:

- $\quad$ Variable $D$ represents all-encompassing public debt. Therefore, it should include state-contingent public debt, like the one that surfaces during crises (see DiazAlejandro (1985) for a detailed recount of how contingent public debt became apparent during Chile's 1982/3 crisis, and Calvo, Izquierdo and Talvi (2002) for recent estimates). State-contingent debt has proven to be large and to contain a sizable unanticipated component. Thus, a SS could take place even though to the naked eye the economy appears safely ensconced within the high-growth region (i.e., far to the left of critical point $\delta^{2}$ ).

- The critical debt level $\delta^{2}$ is a function of the production parameter $\alpha$. Recalling Figure 1, it is clear that $\delta^{2}$ declines as $\alpha$ falls. A negative terms-of-trade shock 
could be captured by a lower $\alpha$. Thus, a deterioration in the terms of trade could plunge the economy into the LGE, causing, as will be argued in the next section, a SS. This observation, incidentally, shows that for economies that are near their critical debt levels, a relatively minor terms-of-trade deterioration can bring about a substantial decline in output growth.

- The model assumes that the government and the private sector have access to capital markets. However, $D$ could also stand for country-risk-adjusted public debt, in which case an increase in country risk implies a larger $D$. Thus, even in the benign case in which the private sector is immune to country risk, $\theta D$ could jump to the low growth region as a result of an increase in country risk. This is relevant for rationalizing the effects of events like the Russian 1998 crisis (see Calvo (1998 a, and 1999), Calvo and Mendoza (2000)), which resulted in an increase in country risk all across EM, and appears to have left in its wake a noticeable growth slowdown in Latin America (see Calvo, Izquierdo and Talvi (2002)).

- Debt levels that can be sustained without inducing low growth, decline with the share of debt that has to be serviced on the basis of distortionary taxes (i.e., as $\theta$ increases). Thus, if labor supply were inelastic, for example, it would be optimal to raise labor taxes and set $\theta=0$. However, tax evasion may make this impossible or at least impractical. This suggests the key role of tax reform and adequate fiscal institutions for growth and stability. 


\section{Sudden Stop and Home Goods}

So far our discussion did not require any reference to utility functions, because in the model there is complete separation between production and consumption decisions. The latter is, in general, essential information to compute current accounts (and, hence, address the issue of SS) or model the behavior of the real exchange rate (which requires bringing to the picture home or nontradable goods).

Suppose that there exists a representative individual whose utility function is time-separable, the subjective rate of discount is constant and (for simplicity) equal to the international rate of interest $r .{ }^{6}$ The instant utility function will be denoted $u(c, h)$, where $c$ and $h$ stand for consumption of tradable and home goods, respectively. Output of home goods is described by a concave production function $f(x)$, where $x$ stands for input of tradables. Functions $u$ and $f$ satisfy the standard regularity conditions. The analysis will be centered on interior solutions.

The above assumptions guarantee that optimal consumption of tradables and nontradables, and production of nontradables will be constant over time. The budget constraint under these conditions boils down to

$$
r[V-(1-\theta) D]=c+x
$$

where time subscripts are dropped because all paths are constant over time. The squarebracketed expression is net wealth after taking into account distortionary taxes (netted out from $V$ ) and non-distortionary taxes, $(1-\theta) D$. Thus, the optimal (market equilibrium)

\footnotetext{
${ }^{6}$ For a discussion of this model in the more general case in which the rate of discount is different from the international interest rate, see Calvo (1998 c). The latter also addresses welfare issues and the impact of controls on capital outflows that will be skipped in the present paper.
} 
consumption and production plan is obtained by solving the following problem:

$$
\max _{c} u(c, f(r[V-(1-\theta) D]-c))
$$

Solving (11) yields the following familiar first-order condition, equating the marginal rate of substitution between tradables and nontradables and the respective marginal rate of transformation:

$$
\frac{u_{h}(c, f(r[V-(1-\theta) D]-c))}{u_{c}(c, f(r[V-(1-\theta) D]-c))}=\frac{1}{f^{\prime}(r[V-(1-\theta) D]-c)}=p
$$

where $p$ is the relative price of home goods with respect to tradables (i.e., the inverse of the real exchange rate). By (12), equilibrium $c$ and $p$ are functions of net wealth.

Moreover, by equations (4) and (6)

$$
V-(1-\theta) D=\frac{\alpha-z}{r-z}-D
$$

Recalling that $\bar{z}<r$, condition (9) for the existence of a HGE requires, that $\alpha>r$. Thus, by (13), $V$ is an increasing function of $z$. This can be employed to show, incidentally, that, if HGE and LGE coexist, then HGE Pareto dominates LGE, as expected.

By equations (10) and (13), the Current Account (Surplus) at time 0, $C A_{0}$, satisfies, assuming that $K_{0}=1$ and is entirely owned by domestic residents,

$$
C A_{0} \equiv \alpha-z-r D-c-x=-\frac{\alpha-z}{r-z} z
$$

Hence, $C A_{0}<0$ on HGE and $C A_{0}=0$ on LGE. Consequently, as the economy switches from high to low growth, the current account deficit exhibits a discontinuous collapse to zero. Thus, SS takes place, since a non-monetary economy like the present one, $-C A_{0}=$ Capital Inflows at time 0. Moreover, assuming that consumption of nontradables is a 
"normal" good, it follows that, given $p$, consumption of nontradables falls as net wealth (i.e., $V-(1-\theta) D)$ declines. Therefore, by equation (12), as growth collapses, $x$ falls and $f^{\prime}(x)$ rises, implying that the SS would be accompanied by real depreciation (i.e., $p$ falls). Clearly, in this case GDP will also collapse because the output of nontradables falls. All of these results are fully in line with empirical observations (see Calvo and Reinhart (2000), and Calvo, Izquierdo and Talvi (2002)).

1. Money. The model can easily be extended to a monetary economy. For example, suppose the demand for money is subject to a cash-in-advance constraint, such that

$$
\text { demand for nominal money } \equiv M^{d}=E(c+p h) \text {, }
$$

where $E$ is the nominal exchange rate (i.e., the price of foreign exchange in terms of domestic currency). Thus, first-order conditions (12) remain intact and, if the representative individual internalizes the government budget constraint, one can show that money is superneutral, in the sense that, along steady states, the real side of the economy is invariant to the presence of money.

Thus, recalling that under the crisis scenario highlighted above (i.e., $D$ unexpectedly moves from the high to the low growth region) $c+p h$ declines, it follows that, given $E$, the demand for money will exhibit a discontinuous fall. Consider the case in which $E$ is fixed. Therefore, the SS will be associated with an unexpected drop in international reserves. If the latter is high enough, a BOP crisis would ensue. Notice that the model gives an anti-Krugman rationale for the BOP crisis (Krugman (1979)). The crisis in the present model is entirely rooted in real factors: SS comes first, BOP follows. Policy implications are also very different. For example, Krugman crises can be 
prevented by following a tighter fiscal policy, whereas in the present model tighter fiscal policy (if based on higher tax rates) could actually trigger the crisis. Not because fiscal balance is undesirable, but because the instruments to achieve it are distorting! Once again, what the present model highlights is the importance of improving fiscal

\section{institutions.}

2. Anticipated Crises. Although I believe SSs contain a significant unanticipated component, the present model can also rationalize the case in which a SS is fully anticipated. In the first place, notice that, in general, investment decisions are predicated on

$$
\operatorname{sgn}\left[\int_{t}^{\infty} \alpha\left(1-\tau_{s}\right) e^{-r(s-t)} d s-1\right] .
$$

The integral in expression (16) equals the present discounted value of net-of-taxes return on a unit of investment. Thus, investment will take place when the latter exceeds its cost $(=1)$, i.e., when the sign in expression (16) is positive; moreover, if (16) is negative, no investment will occur. As expected, when $\tau$ is constant expression (16) boils down to (5). Consider now the situation in which from time 0 to $T$ debt is zero, but everyone knows that at time $T$ the public sector will be loaded with debt $\theta D=\delta^{2}+\varepsilon$ (where, it should be recalled, $\delta^{2}$ is the critical level of distortionary debt beyond which low growth is the only equilibrium solution, recall Figures 1 and 2, and $\varepsilon$ is a positive number). Moreover, suppose that on the interval $(0, T]$ the tax rate $\tau=0$; afterwards, $\tau$ is set at a constant level necessary to service debt $D$. One can easily show that as $\varepsilon$ converges to 0 , investment will be set at its maximum level in the interval $(0, T]$, and $z_{t}=0$, for $t>T$. Thus, a fully anticipated growth collapse at time $T$ would take place. Will this result in a SS? Since the 
growth crisis is fully anticipated and consumers have access to the capital market (and are not subject to taxes that distort the consumption time profile), consumption will remain undisturbed. However, investment will go from $\bar{z} K_{t}$ to zero. Therefore, at the onset of the growth crisis, a SS will take place. ${ }^{7}$

In what follows I will show how to construct a monetary example which would be a polar opposite to Krugman's (1979). Suppose that the economy starts with zero debt, a positive fiscal deficit, and zero distorting taxes, $\tau$. Clearly, debt will be increasing throughout time and, if policy remains the same, it will eventually reach the critical level $\delta^{2}$. At this juncture, the government eliminates fiscal deficit by resorting to the inflation tax to cover the primary deficit (as in Krugman (1979), and services the outstanding debt as in Section II (i.e., employing distorting taxes). Obviously, the economy will display high growth until net output-distorting debt reaches the critical level $\delta^{2}$, and then switch to low growth forever. ${ }^{8}$ The monetary economy under fixed rates will again display a sudden loss of international reserves at crisis, reflecting the effect of anticipated inflation (as in Calvo (1987)). One could even generate a BOP crisis a la Krugman (1979) if public debt includes (with a negative sign) international reserves. If, for example, the critical minimum level of reserves is zero, it can be shown that the crisis coincides with full depletion of international reserves, in conjunction with a run against the domestic

\footnotetext{
${ }^{7}$ This does not hold true in the Appendix model because in the latter investment is a continuous function of time. However, even though investment does not display a discontinuous fall, it will show a declining trend.

${ }^{8}$ Again, this does not follow in the Appendix model, in which a lower growth is attained in a continuous manner.
} 
currency. Once again, however, the BOP crisis is inherently real. ${ }^{9}$

The following points are worth making:

- $\quad$ As explained, real depreciation follows from an unanticipated SS, not the other way around. However, given the tendency to focus on exchange rates, a casual observer might conclude that the main culprit was currency over-appreciation. As "proof" she will likely point out that the real exchange rate shows no sign to return to its prior-to-crisis level.

- $\quad$ Suppose the utility function $u$ is homothetic in tradables and nontradables. Hence, given $p$, the demand for nontradables, $h$, is proportional to the demand for tradables, $c$. In particular, during a SS and, given $p$, the demand for nontradables falls in the same proportion as the demand for tradables. Let us focus on the case in which the current account deficit, $C A D$, becomes zero. Then, given $C A D$, the smaller is the domestic supply of tradables (net of international debt and precommitted transfers) in terms of tradables' consumption, $\omega$, the larger will be the proportional drop in $c$ at SS. Consequently, the smaller is $\omega$, the larger will be the fall in $c$ and $h$ (given $p$ ) caused by the SS. Variable $\omega$ measures the economy's ability to supply domestic absorption of tradables. In Calvo, Izquierdo and Talvi (2002), variable $\omega$ is called "un-leveraged absorption of tradable

\footnotetext{
${ }^{9}$ Contrary to this scenario, however, most recent BOP crises seem to have been driven more by an expansion of domestic credit from the central bank than by a fall in the demand for monetary aggregates (see Flood, Garber and Kramer (1996), Kumhof (2000), Calvo (2001)). This issue will be taken up in the next section.
} 
goods;" $\omega$ is shown to vary widely across countries (Argentina and Brazil are shown to have one of the lowest $\omega$ ). Therefore, the same $C A D$ adjustment could have significant differences across countries depending on $\omega$.

- In this model, crises are very tame. There is no room for default, for example. However, this can be easily rectified assuming, for instance, that the government repays only if the default alternative would be more costly. One can show that, abstracting from direct default costs, on the low-growth region the default alternative dominates low growth plus full debt repayment. Thus, (1) even if government is not intent on driving debt beyond the critical level, a bit of uncertainty will generate country risk premia, and (2) in the anti-Krugman example, in which sooner or later the critical threshold is crossed, the critical threshold will be zero. To see this, note that if it was positive and equal to $\bar{D}$, for example, then investors will stop lending before $D$ reaches $\bar{D}$. Otherwise, the "last" loan before reaching $\bar{D}$ will immediately be declared in default, a hardly attractive investment proposition. However, a positive $\bar{D}$ could be generated if there are direct default costs (a realistic assumption).

- The model assumes that output of home goods falls as the cost of raw materials rises or, equivalently, as the real exchange rate rises (i.e., as the relative price of home goods with respect to tradables $p$ falls). In actuality, however, another important factor in nontradables' output contraction during a crisis is Liability Dollarization, i.e., the existence of debt denominated in terms of tradables (dollar 
debt, for short). ${ }^{10}$ Under these conditions, for example, an unanticipated SS could give rise to bankruptcies in the home goods sector, resulting in momentarily lower output. How deep and persistent is the output collapse will depend on bankruptcy legislation and the efficiency of the judicial system, and, of course, it will also depend on how much dollar-indebted is the home goods sector. The latter, incidentally, could be especially large after a capital inflow episode like the one that occurred in EM during the first half of the 1990s.

- The weaker the enforceability of financial contracts, the more likely will be that loans impose collateral constraints, by which the value of attachable assets cannot fall short of a predetermined proportion of the loan. Thus, it has become popular to assume that the loans a firm/individual can take depend on some measure of net worth. ${ }^{11}$ Thus, if the collateral constraint is binding, a depreciation of the real exchange rate, i.e., a fall in $p$, may call for liquidation of productive assets. If we further assume, following Kiyotaki and Moore (1997), that the liquidated assets will go to less efficient hands, then output will suffer a contraction. Thus, a crisis could display a fall in output of nontradables even though, in principle, output would be perfectly price inelastic in absence of the financial shock. Output contraction by this channel does not even require bankruptcy to take place. At any rate, however, these extensions show that the

\footnotetext{
${ }^{10}$ This is one of the key new topics in the EM literature. See, for example, Calvo (2001), Jeane (2001).

${ }^{11}$ This line of research has been pioneered by Kiyotaki and Moore (1997) for the closed economy, and extended to the open economy by Caballero and Krishnamurthy (2001 a, b and 2003), Izquierdo (2000), and others.
} 
financial channel could add to the depth and persistence of the crisis (see DiazAlejandro (1985)). Whereas raw materials are flows, financial obligations are stocks. A stock reversal could actually cause much more damage than a flow cost increase, particularly if the latter is deemed to be temporary.

\section{Sudden Stop and Monetary Policy}

I will conduct the discussion taking as background the previous section's model, focusing on the case in which the SS is largely unanticipated, and causes a credit crunch in the home-goods sector (due to, for instance, collateral constraints or margin calls). ${ }^{12}$ The analysis will center on policies taken after SS, and also policies that can be implemented before SS to cushion its deleterious effects. Clearly, in this model credit is cut because outstanding credit is too large relative to the economy's capacity to repay. Thus, only policies that have an impact on the latter will have a chance of becoming effective. Monetary policy can influence the ability to repay in at least two different ways: (1) managing international reserves, and (2) changing relative prices in the face of price/wage stickiness.

1. Management of International Reserves. A common feature in recent crises is a large expansion of domestic credit from the central bank. As pointed out by Flood, Garber and Kramer (1996) and Kumhof (2000), this feature is not captured by the first-generation Krugman-Flood Garber models (see Krugman (1979), Flood and Garber (1994)). In the latter the crisis is triggered by a sudden decline in the demand for domestic money. Actually, as illustrated by the Tequila crisis (see Calvo and Mendoza (1996 b)), in most

\footnotetext{
${ }^{12}$ Thus, this section departs from the basic model in Section II, and is more speculative than earlier sections.
} 
cases (Argentina and Hong Kong are exceptions) the loss of international reserves is almost entirely driven by domestic credit. The demand for domestic money shows no atypical decline. Can one find a rationale for that?

The following accounting identity is worth recalling:

$$
K I=C A D+\Delta R,
$$

where "errors and omissions" are ignored, and $K I, C A D$, and $\triangle R$ stand for, respectively, capital inflows, current account deficit and accumulation of international reserves, $R$. A SS is reflected in a sharp drop in $K I$. If the central bank lets the exchange rate float, then no reserves will be lost, and the entire adjustment will fall on the current account, calling for a sharp real depreciation (a sharp fall in $p$, in the model's notation). This, in turn, might provoke sizable income redistribution, including bankruptcies in the nontradable sector. Thus, the central bank will have incentives to follow an expansionary policy that places some of its international reserves in private hands (the nontradable sector's, if the main objective is bankruptcy prevention). Pure floating cannot work, because the central bank would not be able to release its reserves (unless they are directly transferred to the fiscal authority). Therefore, under standard practices the central bank will be forced to adopt some kind of pegging accompanied by domestic credit expansion (hopefully before domestic money holders wise up to the impending crisis). This rationalizes the fact (observed in Mexico 1994/5 and Brazil 1998/9) that the SS occurs first, and it is later followed by a currency crisis provoked by the central bank (not only by panicky domestic money holders). ${ }^{13}$ Thus, devaluation follows the SS. Since the latter is contractionary,

${ }^{13}$ This requires changing the anti-Krugman example in Section III to allow for the central bank to issue domestic credit in response to a SS. Central bank hyperactivity during BOP 
this analysis also provides a rationale for contractionary devaluation, a well-known phenomenon in developing countries (see Diaz-Alejandro (1963), Sebastian Edwards (1989)). Notice, however, that under this interpretation, output contraction is not the result of devaluation: SS would be.

This discussion highlights the possible desirability of pegging the exchange rate once a SS is detected. Exchange rate pegging allows the central bank transfer to the private sector its international reserves. ${ }^{14}$ Is pegging responsible for the crisis in a deeper sense? I would not deny the possibility, but the present model shows that the roots of a SS may rest on fiscal dysfunction and be totally divorced from exchange rate policy.

Is central bank credit the best way to help the private sector during a SS? I have some serious doubts, because the new domestic credit will likely go to the public sector (slowing down desirable adjustment in government expenditure), and firms that have access to international credit markets (multinationals). The latter, in particular, are likely to use additional domestic credit to unwind their dollar debts, an attractive proposition in view of impending devaluation, and that central bank credit expansion may momentarily push domestic interest rates for prime borrowers below market equilibrium. Thus, it is

crises, incidentally, is a widely observed fact, as noted by Flood, Garber, and Kramer (1996) and Kumhof (2000).

${ }^{14}$ Once again, this policy would be especially relevant if the private sector suffers a credit crunch. Brazil offers a recent example of this kind of central bank policy, see Financial Times (2002). 
conceivable that domestic credit expansion drains international reserves from the central bank without substantially relieving the pressure on the current account. This bleak scenario, which unfortunately appears not to be uncommon, helps to explain why during a SS, governments might be driven to adopt heterodox policies. For example, controls on capital outflows (e.g., Malaysia 1998), socialization of private debts (e.g., Chile 1982/3, see Diaz-Alejandro (1985)), or controls on the direction of bank credit (Brazil 2002).

A serious difficulty with heterodox policies is that, as a general rule, they imply breaking established rules or implicit contracts, opening up the door for time inconsistency and political economy maneuvers, specifically Wars of Attrition where different groups vie to benefit from central bank credit (see Sturzenegger and Tommasi (1998)). Wars of Attrition result in policymaking paralysis, becoming very hard to know which side will win. The policy impasse, in turn, increases the option value of waiting, which results in further investment and credit contraction-and declining growth (see Calvo (2002)).

One way to get a better outcome might be for the government to offer (or support) exchange rate hedge contracts that will be activated the moment a large devaluation takes place. In this fashion, the loss of reserves would be automatic, helping to ameliorate the after-crisis tug-of-war. It should be noted, however, that government hedges may end up being underpriced, because their price reflects, in part, the government's assessment of the likelihood of crisis. Thus, in order to show the authorities' high confidence in current policies, unrealistically cheap hedges may be offered, increasing the fiscal cost of a crisis and, in terms of the above model, also the 
likelihood of crisis (because contingent net public debt goes up).

2. Wage/Price Stickiness. This phenomenon lies at the heart of the literature on optimal exchange rate regimes and Optimal Currency Areas (e.g., Flood and Marion (1982); Calvo (2001) for a critical assessment). A standard result is that if the economy is hit by a real shock, it is optimal to let the exchange rate free to float. Thus, since a SS is essentially a real shock, one might reason that floating would be optimal-at least, until the dust settles. ${ }^{15}$

Let me first note that, in practice, the choice between fixed and floating exchange rate regimes in the aftermath of a SS often turns out to be just an academic exercise. Many economies are swept away by events and end up devaluing their currencies before the exchange rate issue is even raised! However, Argentina and Hong Kong in 1995 are interesting counterexamples. These economies were able to maintain their Currency Board regimes despite massive loss of international reserves. At any rate, the issue that I would like to raise is whether, subject to having enough international reserves, it may be socially desirable to keep a peg a little longer after a SS, in order to slowdown the relative price adjustment.

As noted, SSs call for sharp changes in relative prices (often involving a real currency depreciation, a fall in $p$ ). Thus, firms saddled with dollar debts, may be forced into costly asset liquidation or outright bankruptcy. Quick convergence to the new set of equilibrium relative prices will bring this situation into the open, and financial chaos

${ }^{15}$ In actuality, however, as shown in the earlier discussion of the monetary economy, a SS gives rise to both real and nominal shocks. Thus, if anything, the standard literature would call for dirty float. 
might ensue. Could a temporary peg make a difference? The instinctive answer is probably "no" because, otherwise, sectors that should see their equilibrium relative price fall, would instead see their quantities contract-resulting in a wash at best. However, this intuition misses and important point, namely, the microeconomics of price setting. To illustrate, suppose that prices are set in a highly competitive environment, such that, under normal circumstances, profits are near zero. Thus, a shock that set initial home good prices above their new full equilibrium level, is observationally equivalent to firms colluding and setting their prices at a higher-than-competitive-equilibrium level. Output will fall but firms' profits may rise. This is not always the case but, in the present context, it is a definite possibility. Therefore, relative price stickiness (brought about by price stickiness plus an exchange rate peg) may help to relieve financial stress. ${ }^{16}$ Consequently, the existence of price-stickiness may be another reason in favor of pegging in response to a SS.

\section{Final Remarks}

- The central message of the paper is that currency crises in EM may just be a sideshow, and that the key factors behind the collapse of economic activity and growth may stem from dysfunctional domestic policies and serious financial vulnerabilities. The latter give rise to sharp changes in market equilibrium in response to relatively minor real shocks. Thus, BOP crises could just be one of the many deleterious effects of a SS.

- The model is silent about the factors that trigger a SS. Any shock that pushes the

${ }^{16}$ For an example in terms of a micro-founded staggered-prices model, see Calvo (2000). 
economy beyond the critical debt level would trigger a SS. It could be an external factor, as Calvo, Izquierdo and Talvi (2002) claimed it was the case recently in Argentina, but it could also be an internal factor, like a domestic political or corporate governance scandal.

- $\quad$ The main policy lesson from the model is that EM should strive to improving fiscal and financial institutions. But, perhaps equally important, policymakers should get ready for the possibility of a SS. They should go through SS drills, much as well-run buildings go through fire drills. Under normal circumstances, fires are low probability events. However, if not well managed, the resulting stampede may dramatically increase the number of casualties.

- As noted, IFIs have a big role to play in coordinating high growth when both high and low growth coexist. Actually, if the model is not misleading, before reaching a SS, there is always a region of indeterminacy in which IFIs could play that role. Outside that region, however, the situation becomes more complicated, because most EM do not qualify for grants (as opposed to loans) from IFIs in response to debt crises (HIPCs are the exception). Moreover, the G 7 have expressed serious concern about Moral Hazard implications of bailout packages. ${ }^{17}$

- Still, IFIs could play a useful role as coordinators of private sector bail-ins, and enforcers of fiscal reform. The former would lower the level of public debt, thus pushing the economy into the high-growth region. Fiscal reform could also be

${ }^{17}$ For a critical assessment of the Moral Hazard view in connection with recent EM crises, see Calvo (2002). 
very effective if it helps to lower tax distortions (e.g., $\theta$ in the present model). If countries are left on their own, these reforms may be hard to implement, because of political reasons. In the Basic Model in Section II, for example, fiscal tightening would be effective if it relies on lowering government expenditure in a credible and sustainable manner, which is usually tangled with serious political economy problems. IFIs could help to break the stalemate by offering "Loans for Reform." If successful, the loans will be fully repaid because fiscal reform would place the economy on the high-growth path.

- However, the model suggests that outside the high-growth region, simple-minded belt-tightening fiscal programs, relying on higher taxes, could be counterproductive in the short run.

- Thus, a literal reading of the model shows that a tax hike will have no effect, given that, in principle, it does nothing about total public debt, $D$, or its distortionary impact, $\theta$. However, higher taxes may help to bring the economy back to high growth. The hard question in this respect is whether a belt-tightening policy will enjoy political support during the transition in which pain is not immediately rewarded by high growth.

- Often during crises tax hikes rely on taxes that are non-distortionary in the short run (i.e., wealth taxes, and, in general, taxes on "sitting ducks"), but which would be highly distortionary if agents anticipated their continuation in the future. Therefore, these taxes are effective if policymakers can credibly ensure the private sector that they will be eliminated as soon as the emergency 
situation blows over. Conceivably, IFIs could help to reinforce credibility in this context, although I am highly skeptical: in the future there will likely be a new set of policymakers both in the world at large, and the country in question-making enforceability extremely difficult.

- Finally, a technical note. The paper shows that SSs can be both anticipated or unanticipated. My conjecture, though, is that SSs contain a large element of surprise, and that the recent episodes have a lot to do with the Russian 1998 crisis, and resulting perception that EM securities constitute a much more risky asset class than previously thought. However, this should not be read as belittling the relevance of domestic factors. On the contrary, as the model shows, the critical debt level is intimately related to domestic institutions. Moreover, given the strong non-linearities implied by the model, domestic factors could be powerful multipliers of external shocks. The problem for the econometrician is that nonlinearities imply that, faced with the same external shock, some economies enter into deep crisis, while others escape totally unscathed. Moreover, those that are drawn into crisis will likely trigger additional domestic factors that contribute to the depth of the crisis (like political instability). Thus, the econometrician could wrongly infer that domestic factors are the sole determinants of these crises. Furthermore, if the number of crisis countries is small (e.g., at the time of writing, Argentina was the only large Latin American country that went into deep crisis after the Russian shock), empirical estimates will suffer from well-known smallsample problems. 


\section{Appendix}

The main purpose of this section is to show that the SS follows from the existence of tax distortions and not from the knife-edge feature of the model in the text. With that in mind, I will modify the previous model and assume that investment is subject to adjustment costs. More concretely, I will assume that the output cost per unit of capital associated with capital growth $z$ is portrayed by $\varphi(z)$, where function $\varphi$ is strictly convex and twice-continuously differentiable (implying $\varphi^{\prime \prime}>0$ ). Notice, incidentally, that in the text I assume $\varphi(z)=\mathrm{z}$. Thus, to stay close to that model in a neighborhood of 0 , I will further assume $\varphi(0)=0$, and $\varphi^{\prime}(0)=1$; moreover, I will assume that there exists $\underline{z}$ and $\bar{z}$ such that $\underline{z}<0<\bar{z}<r$, such that $\varphi$ is defined on that open interval, and $\lim \varphi^{\prime}(z)=\infty$ as $z$ converges to $\bar{z}$ from the left, while $\lim \varphi^{\prime}(z)=-\infty$ as $z$ converges to $\underline{z}$ from the right. Moreover, to simplify the analysis, I make the realistic assumption that $\lim \varphi(z)$ as $z$ converges to $\underline{z}$ from the right is finite (specifically, it does not converge to $\infty$ ).

Therefore, the value of the firm at time $0, V$, satisfies (cf. equation (4)):

$$
V=\frac{\alpha(1-\tau)-\varphi(z)}{r-z}
$$

Hence,

$$
\operatorname{sgn} \frac{\partial V}{\partial z}=\operatorname{sgn}\left[-\varphi^{\prime}(z)(r-z)+\alpha(1-\tau)-\varphi(z)\right]
$$

and, if $\partial V / \partial z=0$, then

$$
\operatorname{sgn} \frac{\partial^{2} V}{\partial z^{2}}=-\varphi^{\prime \prime}(z)(r-z)<0
$$

Thus, first-order conditions are sufficient for a maximum of $V$ with respect to $z$, because 
$V$ does not contain a local minimum.

Plugging budget constraint (6) to substitute for $\tau$ in (19), we get

$$
\alpha-\theta D(r-z)-\left[\varphi(z)+\varphi^{\prime}(z)(r-z)\right] \equiv J(z, D)
$$

Previous assumptions ensure that $J(z, D)$ converges to $\infty$ as $z$ goes to $\underline{z}$ from the right, and to $-\infty$ as $z$ goes to $\bar{z}$ from the left. Hence, equilibrium existence is ensured for all $D$. It can further be shown, by $(21)$, that $J_{z}(z, 0)<0$ for all $z \in(\underline{z}, \bar{z})$. Thus, equilibrium is unique for $D=0$. This result should not surprise us because if $D=0$, there is no distortionary taxation. Moreover, as a general rule, under uniqueness, equilibrium is a continuous function of $D$. This shows that in order to get the SS discontinuities discussed in the text, it is, as a general rule, necessary for the model to exhibit multiple equilibria (before imposing the equilibrium-selection principle according to which the economy settles on the highest-growth equilibrium).

I will now show an example where equilibrium is not unique (in absence of the equilibrium-selection principle). By (21), and recalling that $\varphi(0)=0$ and $\varphi^{\prime}(0)=1$, we have

$$
J(0, D)=\alpha-\theta D r-r .
$$

Let $D^{c}$ be such that $J\left(0, D^{c}\right)=0$. This implies that if $D=D^{c}$, then $z=0$ maximizes the value of the firm $V$ with respect to $z$. Clearly, by (22),

$$
\theta D^{c}=\frac{\alpha-r}{r}>0
$$

Moreover, by (21) and (22), at $D=D^{c}$,

$$
J_{z}\left(0, D_{c}\right)=\frac{\alpha-r}{r}-\varphi^{\prime \prime}(0) r .
$$


Hence, given $r$, for $\alpha$ sufficiently large or $\varphi^{\prime \prime}(0)$ sufficiently small, we can ensure that $J_{z}\left(0, D^{c}\right)>0$. Thus, drawing the $J$ function, given $D$, under these conditions readily shows that, if $D=D^{c}$, the economy will exhibit at least three equilibrium solutions (illustrated by the solid line in Figure 3). Moreover, by (21), the $J$ function shifts down as $D$ increases. Hence, there exists some $\bar{D}>D^{c}$ such that $J(z, \bar{D})<0$ for all $z \in[0, \bar{z})$. However, the "bad" negative growth equilibrium is never lost (illustrated by the dashed line in Figure 3). This implies that there will be some critical $D$ (equivalent to $\delta^{2} / \theta$ in the main text's model) such that a growth collapse, SS, etc., will take place even if $D$ suffers a slight increase. Moreover, since the richer model could depict any number of equilibria, there could be succession of SSs as $D$ increases.

In closing, notice that the share of distorting debt in output at time zero, $\theta D^{c} / \alpha$, satisfies, by (23),

$$
\theta D^{c} / \alpha=\frac{1-\frac{r}{\alpha}}{r} .
$$

Thus, distorting debt in the multiple-equilibria example can be made as small a share of output as desired by selecting $\alpha$ sufficiently close to $r$, and $\alpha>r$. This shows that the example does not require unrealistically high debt ratios.

(Insert Figure 3 here) 


\section{REFERENCES}

Caballero, Ricardo J., and Arvind Krishnamurthy, 2001 a, "International and Domestic Collateral Constraints in a Model of Emerging Market Crises," Journal of Monetary Economics, 48, 3, pp. 513-548.

Caballero, Ricardo J., and Arvind Krishnamurthy, 2001 b, “A Vertical Analysis of Crises and Central Bank Interventions," manuscript, MIT, October.

Caballero, Ricardo J., and Arvind Krishnamurthy, 2003, “Excessive Dollar Debt:

Financial Development and Underinsurance," Journal of Finance, 58, 2, 867-94.

Calvo, Guillermo A., 1987, "Balance of Payments Crises in a Cash-in-Advance

Economy," Journal of Money, Credit and Banking, 19, 1, February, pp. 19-32.

Calvo, Guillermo A., 1998 a, "Understanding the Russian Virus: with special reference to Latin America," manuscript, October. <www.bsos.umd.edu/econ/ciecalvo.htm>

Calvo, Guillermo A., 1998 b, "Capital Flows and Capital-Market Crises: The Simple Economics of Sudden Stops," Journal of Applied Economics (CEMA), 1, 1, November, pp. 35-54.

Calvo, Guillermo A., 1998 c, "Growth, Debt, and Economic Transformation: The Capital Flight Problem," in F. Coricelli, Di Matteo, F. Hahn (eds.) New Theories in Growth and Development, Palgrave Macmillan. Working Paper No. 5, Center for International Economics, University of Maryland, October 1994.

Calvo, Guillermo A., 1999, “Contagion in Emerging Market: When Wall Street is the Carrier," manuscript, February. $<$ www.bsos.umd.edu/econ/ciecalvo.htm $>$

Calvo, Guillermo A., 2000, "Notes on Price Stickiness: With Special Reference to Liability Dollarization and Credibility," manuscript, December. 
$<\underline{\text { www.bsos.umd.edu/econ/ciecalvo.htm }>}$

Calvo, Guillermo A., 2001, "Capital Markets and the Exchange Rate, with special reference to the Dollarization Debate in Latin America," Journal of Money Credit and Banking, 33, Part 2, May, pp. 312-334.

Calvo, Guillermo A., 2002, "Globalization Hazard and Delayed Reform in Emerging Markets," Economia, 2, 2, Spring, pp. 1-29.

Calvo, Guillermo A., Alejandro Izquierdo, and Ernesto Talvi, 2002, "Sudden Stop, the Real Exchange Rate, and Fiscal Sustainability: Argentina’s Lessons,” manuscript, Inter-American Development Bank, IADB, Washington, D.C., July.

Calvo, Guillermo A., and Enrique G. Mendoza, 1996 a, "Petty Crime and Cruel Punishment: Lessons from the Mexican Debacle" American Economic Review, Papers and Proceedings, 86, 2, May, pp. 170-175.

Calvo, Guillermo A., and Enrique G. Mendoza, 1996 b, “Mexico’s Balance-of-Payments Crisis: A Chronicle of a Death Foretold," Journal of International Economics, 41, pp. $235-264$.

Calvo, Guillermo A., and Enrique G. Mendoza, 2000, “Capital Market Crises and Economic Collapse in Emerging Markets: An Informational-Frictions Approach," American Economic Review, Papers and Proceedings, 90, 2, May, pp. 59-64.

Calvo, Guillermo A., and Carmen M. Reinhart, 2000, "When Capital Flows Come to a Sudden Stop: Consequences and Policy," in Peter B. Kenen and Alexander K. Swoboda (eds.) Reforming the International Monetary and Financial System, Washington, DC: International Monetary Fund.

Calvo, Guillermo A., and Carmen M. Reinhart, 2001, "Fixing for Your Life," in Susan 
M. Collins and Dani Rodrik (eds.) Brookings Trade Forum, Brookings Institution Press, pp. 1-58.

Diaz-Alejandro, Carlos F., 1963, “A Note on the Impact of Devaluation and the Redistribution Effect," Journal of Political Economy, 71, 6, pp. 577-80.

Diaz-Alejandro, Carlos F., 1985, “Good-bye Financial Repression, Hello Financial Crash," Journal of Development Economics, 19, 1, pp. 1-24.

Dornbusch, Rudiger, Ilan Goldfajn, and Rodrigo O. Valdés, 1995, "Currency Crises and Collapses," Brookings Papers on Economic Activity, 2, pp. 219-293.

Eaton, Jonathan, 1987, "Public Debt Guarantees and Private Capital Flight," World Bank Economic Review, January, pp. 337-95.

Edwards, Sebastian, 1989, Real Exchange Rates, Devaluation, and Adjustment, Cambridge, Massachusetts: MIT Press.

Financial Times (2002), "Brazil Pledges Loans to Companies,” August 13, pp. 1.

Flood, Robert P., and Nancy P. Marion, 1982, “The Transmission of Disturbances under Alternative Exchange-Rate Regimes with Optimal Indexing," Quarterly Journal of Economics, 97, 1, February, pp. 43-66.

Flood, Robert P., and Peter M. Garber, 1994, Speculative Bubbles, Speculative Attacks and Policy Switching, Cambridge, MA: MIT Press.

Flood, Robert P., Peter M. Garber, and Charles Kramer (1996). “Collapsing Exchange Rate Regimes: Another Linear Example,” Journal of International Economics, 41, pp. 223-234.

Izquierdo, Alejandro, 2000, "Credit Constraints and the Asymmetric Behavior of Asset Prices and Output under External Shocks," manuscript, Washington, DC: Inter- 
American Development Bank.

Jeanne, Olivier, 2001, "Why Do Emerging Economies Borrow in Foreign Currency?" presented at the 2001 meeting of LACEA, Montevideo, Uruguay, October 18-20.

Kiyotaki, Nobuhiro, and John Moore, 1997, “Credit Cycles,” Journal of Political Economy, 105, 2, April, pp. 211-248.

Krugman, Paul R., 1979, “A Model of Balance-of-Payments Crises,” Journal of Money, Credit, and Banking, 11, August, pp. 311-325.

Kumhof, Michael, 2000, “A Quantitative Exploration of the Role of Short-Term Domestic Debt in Balance of Payment Crises," Journal of International Economics, 51, pp. 195-215.

Sturzenegger, Federico, and Mariano Tommasi, 1998, The Political Economy of Reform, Cambridge, MA: MIT Press. 
Table 1. Sudden Stop

\begin{tabular}{|c|c|}
\hline Country/Episode & SS (\% of GDP) \\
\hline Argentina, 1982-83 & 20 \\
\hline Argentina, 1994-95 & 4 \\
\hline Chile, 1981-83 & 7 \\
\hline Chile $^{1}, 1990-91$ & 8 \\
\hline Ecuador, 1995-96 & 19 \\
\hline Hungary, 1995-96 & 7 \\
\hline Indonesia, 1996-97 & 5 \\
\hline Malaysia $^{1}, 1993-94$ & 15 \\
\hline Mexico, 1981-83 & 12 \\
\hline Mexico, 1993-95 & 6 \\
\hline Philippines, 1996-97 & 7 \\
\hline Venezuela, 1992-94 & 9 \\
\hline South Korea, 1996-97 & 11 \\
\hline Thailand, 1996-97 & 26 \\
\hline Turkey, 1993-94 & 10 \\
\hline
\end{tabular}

Sources: Calvo and Reinhart (2000), from World Bank, World Debt Tables, various issues and Institute for International Economics, Comparative Statistics for Emerging market Economies, 1998.

${ }^{1}$ Sudden Stop owing to the introduction of controls on capital inflows. 
Figure 1. Equilibrium Determination

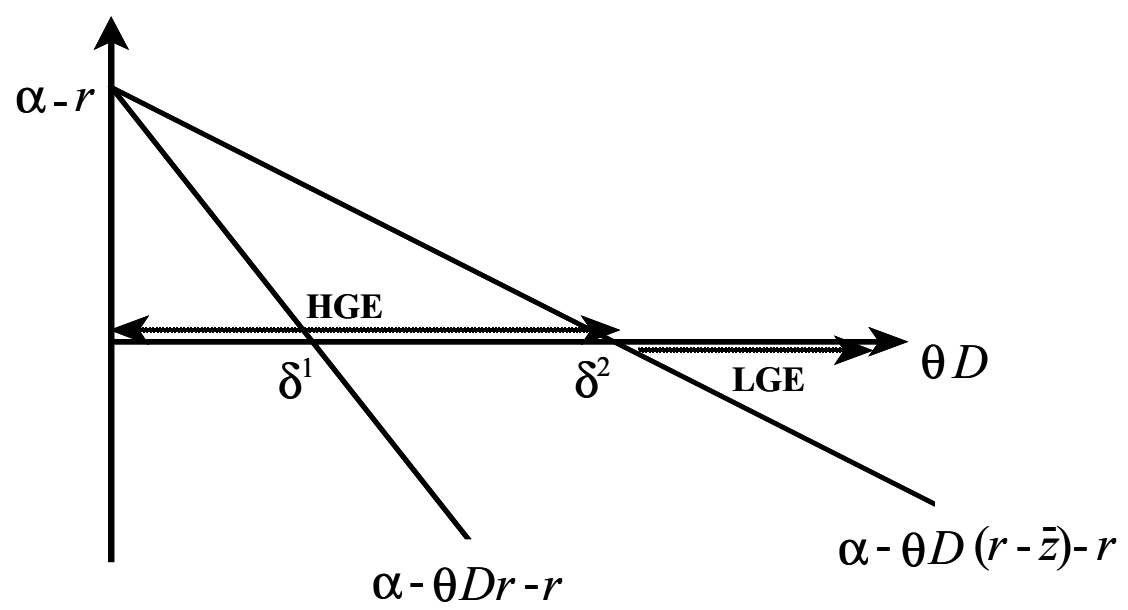

Figure 2. Equilibrium Growth

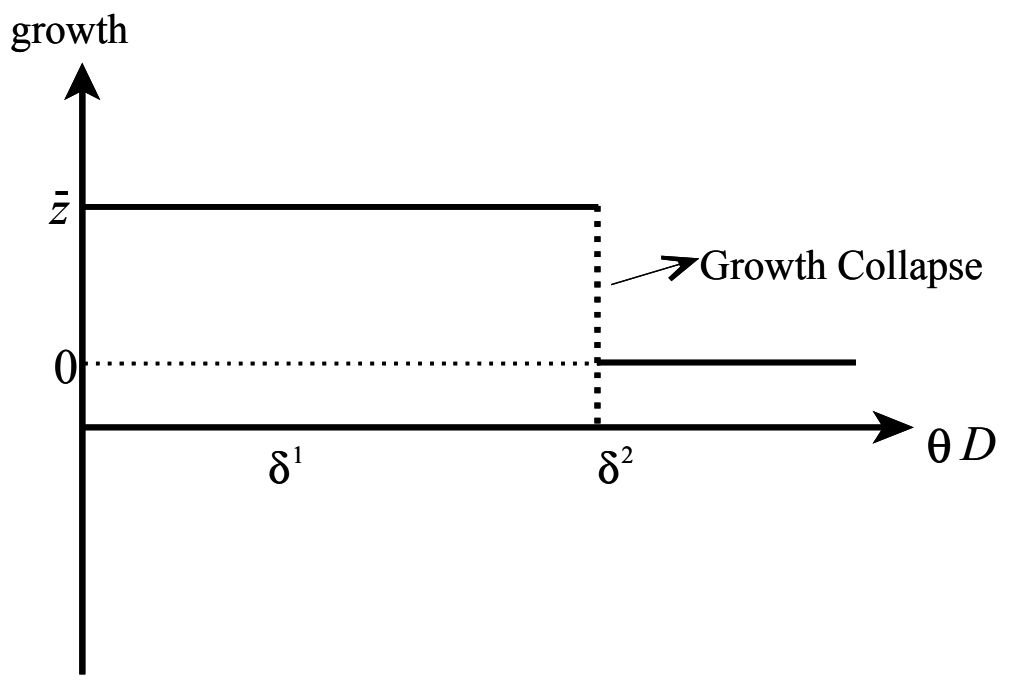


Figure 3. Discontinuous Equilibrium Mapping

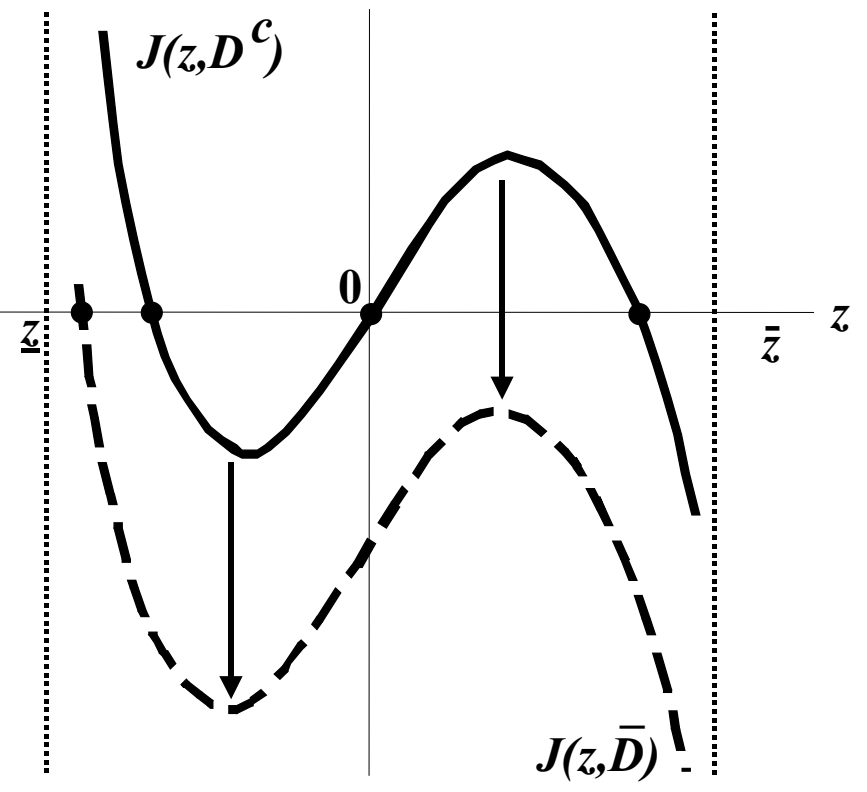

